\title{
Land Resources Usage Constraints and Their Temporal Change in Bale Eco-Region, Southeast Ethiopia
}

\author{
Elsabet Takele Gebeyehu \\ Department of Ecosystem and Biodiversity Conservation, Medda Welabu University, Bale Robe, Ethiopia \\ Email address: \\ elsatakele02@gmail.com
}

To cite this article:

Elsabet Takele Gebeyehu. Land Resources Usage Constraints and Their Temporal Change in Bale Eco-Region, Southeast Ethiopia. International Journal of Natural Resource Ecology and Management. Vol. 5, No. 1, 2020, pp. 6-13. doi: 10.11648/j.ijnrem.20200501.12

Received: December 12, 2019; Accepted: January 18, 2020; Published: February 10, 2020

\begin{abstract}
Usage of land resources to meet the demands of human being has an impact on the land resources. The purpose of the study was to investigate the land resource usage constraints and their temporal change in Bale Eco Region, Southeast Ethiopia. Both qualitative and quantitative cross sectional study designs were employed. Data was collected using HH survey, in depth interview, focus group discussion and field observation. Data analysis, descriptive and inferential statistics were implemented by using SPSS software version 20. Chi-Square test, frequencies and percentage were used to compare differences among variables with respect to the three agro-ecologies and statistical significance was decreased at $\mathrm{P} \leq 0.05$. Qualitative data was first transcribed to texts in local language then retranslated to English for writing the report. Data analysis was done after categorizing the transcripts. The information obtained from quantitative and qualitative sources were triangulated to ensure the relevance of the results of the study. Based on the finding of the study trends of land holding probability $(\mathrm{p}=0.00)$ and land productivities $=(0.00)$, were significantly difference. Physical, technological and extension services were among the constraints that are identified to influence land and other natural resources utilization in the three agro-ecologies of BER. Lack of technology and lack of science based knowledge were among of the critical constraints that reported by majority of the respondents that limit them from utilizing their land resources. Almost in all agro-ecologies, low and erratic rainfall, climate variability, drought, inaccessibility, lack of water sources was the common constraints of. It is recommended that concerned bodies should minimize constraints of responsible land resource utilizations and temporal natural resources degradation in BER.
\end{abstract}

Keywords: Agro-ecology, Constraints, Land Resource, Temporal Change, Proper Usage of Land Resource

\section{Introduction}

Natural resources are things that come from nature such as plants, animals, soil, minerals, water sources all about these are the result of land (e.g., sunlight, fossil fuels), air, and. These natural resources are used to meet the needs of all living things including people. The term land resources can include agricultural and mineral assets as well as resources associated with water and forests [1].

Various frameworks can be employed to distinguish the land resources. One recent approach distinguishes between provisioning services (those responsible for supporting human life), regulating services, cultural services, and supporting services [2] Those services support human livelihoods through provide basic soil and water resources for crop and livestock production; regulating air, water, and climatic processes; supporting the biophysical processes of photosynthesis, soil formation and nutrient cycling; and helping provide a diversity of social, cultural, spiritual, recreational aspects to life [3].

Much land was set aside for conservation; shift and marginalizing local people and make unfriendly them from traditional resource areas [4]. In most of the African countries, land use/cover change is the main deriver of land degradation; and its effect even more obvious in highland and mountainous landscapes [5].

Constraints to execute proper land resources management could be physical, technological, economic, institutional, legal, cultural, or environmental in nature [6]. For example, challenges of natural resources management such as urbanization and expansion of agriculture can influence systems directly and indirectly through their effects on 
climate variables such as soil-moisture system. Socioeconomic processes, including land-use change (e.g., forestry to agriculture; agriculture to urban area) and land-cover modification (e.g., ecosystem degradation or restoration) can also result on temporal change. Due to the strong influence of non-climate factors on agriculture and, to a lesser extent on forestry, especially management practices and technological changes, as well as market prices and policies related to subsidy result in change in species composition [6]. Land use and land cover plays an important role in global environmental change and sustainability including response to climate change effects on ecosystem structure and function, species and genetic diversity, water and energy balance, and agro-ecological potential are also change [7].

The key gaps and constraints that negatively affect the quality of intervention and up-scaling of successful practices for sustainable land management in Ethiopia are Policy legislation and implementation constraints, weak linkages among various disciplines like poor coordination among research, extension and education has affected. Formal technology development and the transfer of technologies from researchers to local experts and local communities, particularly the farmers are another constraint. According to [8], although the government has invested huge sums of public money in setting up the institutional framework for the national agricultural research, education, and extension systems, there seems to be no strong functional linkages among them.

Incomplete technology packages like lack of proper integration, lack of introduced practices with indigenous knowledge and practices, incompleteness of available technologies to address the requirements of the diverse agroecological conditions of the country and lack of proper consideration of the socio-economic setting of the different communities during introduction of technologies are some of the factors reported by stakeholders as negatively affecting the success improvements to land resource management [8].

The BER is a priority area for the conservation of ecosystems. There are many designated protected areas of land in Ethiopia including national parks, wildlife reserves, priority forests, biosphere reserves and community conservation areas. In the centre is the Bale mountain national park, the largest area of Afro alpine in Africa. BER is part of the Afro Montana biodiversity hotspot that belongs to the 34 global biodiversity hotspots. It harbors several endemic but threatened species of animals and plants. It is also an area that has natural features of high tourist attraction; hence strong tourism value [9].

The Harena forest covering the southern part of the mountain is the second largest moist tropical forest in Ethiopia. However, the Harena forest is degrading due to land conversion processes related to the internal population growth and poverty cover [10]. In Harena Buluk and Delo Mena Woredas, presents the key changes in terms of land cover that has taken place. Over the past two decades for each of the tow Woredas, focusing on the integrity and connectivity of the Harena Forest and the area's key land resource and conservation values. In Harena Buluk, significant temporal changes have taken place over the past two decades in terms of land cover [10].

The overall objective of the study has been made to review the nature and level of existing utilization of land constraints' and their opportunities to cause temporal change in 'BER. Knowing all the causative constraints is critical to find alternative solution for economic and social development by using proper utilization of land in the three agro-ecologies of BER. The study also identified constraints in proper utilization of land and possible solution that ensure sustainable utilization of land in the BER and minimize the rate of environmental change. However, our country continues to face environmental degradation unless we put together our handprints to our surrounding for improving environment in a sustainable way through integrating legal instruments, economic instruments and education.

\section{Materials and Methods}

Both qualitative and quantitative study designs were employed. Among quantitative study, cross-sectional household surveys were used in BER to collect relevant information that addresses the study objectives. Among qualitative study designs, Focus Group Discussion (FGD), in-depth interview and field observations were used.

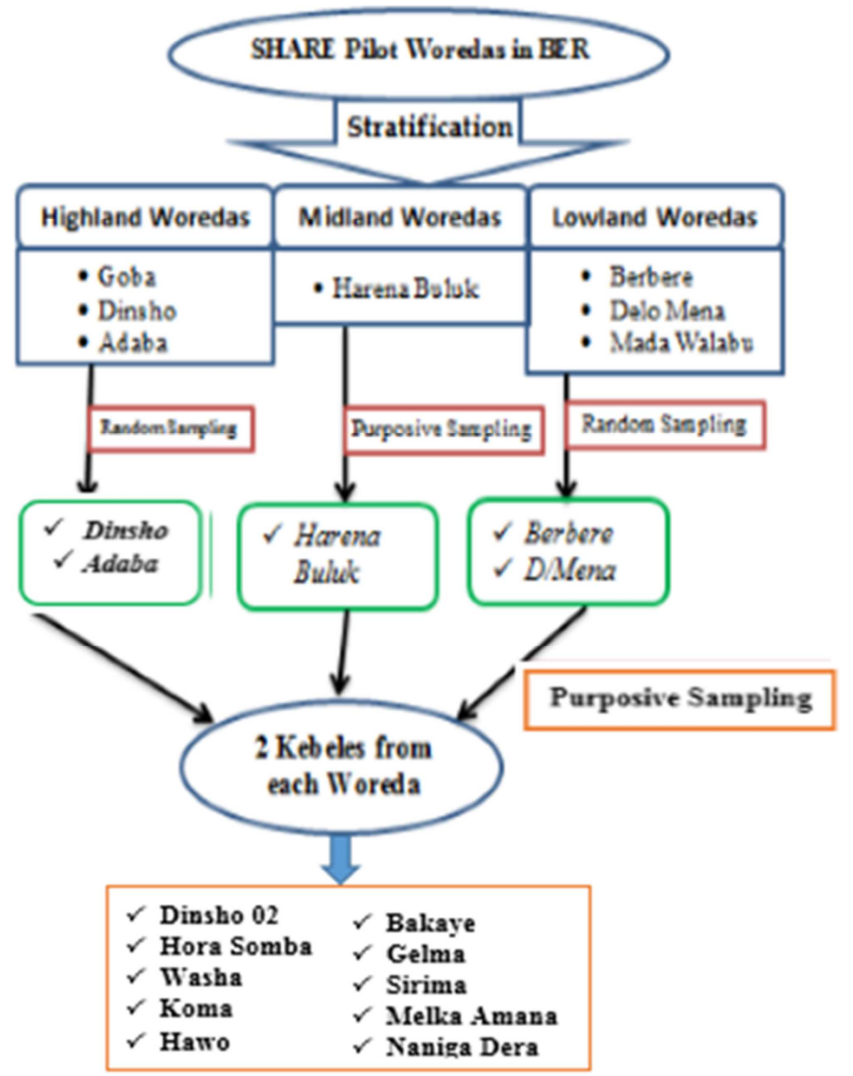

Figure 1. Schematic presentation of sampling procedure of assessment of land resource utilization and their temporal change at BER, 2017.

\subsection{Sampling Technique and Sample Size}

In this study, multi-stage sampling procedures was 
employed (Figure 1). The districts/Woredas in BER were stratified into highland, midland and lowland agro-ecologies. Out of the total highland midland, and lowland Woredas of BER, five Woredas (two from highland : Dinsho and Adabaa Woredas, one from midland, Harenabulke and two from lowland, Berbere and DeloMena Woredas were selected purposively by expert recommendation from their strata by considering best represents of each agroecologies. Accordingly, Adaba and Dinsho from highland Woredas, Delo Mena and Berbere from lowland Woredas, and HarenaBuluk from midland were selected. From each Woredas, two kebeles that best represents the agro-ecologies of the Woreda were selected through purposive sampling method.

The sample size was proportionally allocated to each kebele to draw the sample households. Hence, sample households were selected from each kebele by random sampling method using lottery technique from the sampling frame (i.e. complete household lists) of each Kebele.

The sample size was calculated using a standard formula [11].

$$
\mathrm{n}=\frac{z^{2} p q}{d^{2}}=\frac{1.96^{2} \times 0.5 \times 0.5}{0.05^{2}}=\frac{0.9604}{0.0025}=384
$$

Where: $n$ is sample size, $z$ is statistical certainty usually chosen at $95 \%$ confidence level $(z=1.96), p$ is proportion of population having desired characteristics $(p=0.5), q$ is $1-p$ and $d$ is error accepted by researcher $(5 \%)$.

The participants of the FGD were purposively selected among youths, women and elders by considering as they provide sufficient information about NR usage constraints in the study area. Fifteen FGDs that consists an average of seven participants were conducted. Moreover, 30 key informants (three from each kebele) were participated in an in-depth interview were purposively selected.

Table 1. Number of house hold and sample size per kebele.

\begin{tabular}{lll}
\hline Name of Woreda Name of kebele & Number of HH & Sample size \\
\hline DinshoDinsh-02 & 1776 & 17 \\
Hora soba & 1880 & 18 \\
Adaba Koma & 6582 & 63 \\
Washa & 6059 & 58 \\
Harena Buluk Hawo & 4282 & 41 \\
Bakaye & 3134 & 30 \\
Dello-Mana Nanigadera & 4238 & 41 \\
Malka Amana & 3865 & 37 \\
Berbera Galma & 2925 & 28 \\
Sirima & 5328 & 51 \\
Total & 40,069 & 384 \\
\hline
\end{tabular}

\subsection{Method of Data Collection}

Data was collected from both primary and secondary sources between December 2015 and May 2016. Primary data was collected through semi-structured interview, FGD, field observations and in-depth interviews. The same data collection methods were also used by [12]. (i.e. semistructured interviews) in Bulgaria; [13]. In Greece while [14], used in New Zealand for conducting similar and related studies. The secondary data was obtained from review of organizational reports of study Woredas, Farm Africa, SOS Sahel, Bale Forest and Wildlife Enterprise, SHARE and other relevant organizations.

Quantitative and qualitative data were collected through household survey, FGD, key informants interview and field observation. Regarding the household survey, semistructured questionnaires were employed to collect information on background and socio-economic characteristics of the sample households, on current economic activities of local communities, contribution of natural resource usages to local communities' economic activities, constraints to use existing natural resources and temporal variation in natural resources in different agroecologies of BER. The questionnaires that were initially prepared in English were translated to Afan Oromo. The questionnaires were pre-tested to check their validity and adjustments made where necessary on some households in the study woredas. The interviews were conducted by researcher with the help of six local enumerators and close supervision of five researchers from Madda Walabu University. Local enumerators were recruited from the study area and one-day induction training was given to them.

Totally, 15 FGDs (10 with elders, women's and youths, and five with woreda experts) and key informants interview were carried out by using checklists prepared on economic activities, usage of natural resource, constraints to use existing natural resources and temporal variation of natural resources and other related issues..

In addition, personal observation were employed to identify economic activities, usages and natural resources, constraints to use existing natural resources and current situation of natural resources in the study area.

\subsection{Method of Data Analysis}

Descriptive (percentage) and inferential (Chi-square test) statistics were used to analyze quantitative data using SPSS Version 20 at $95 \%$ level of significance. The qualitative data gathered through FGD and key informant interviews from youths, women and elders were transcribed and organized into themes. Thematic content analysis was done after categorizing the transcript, narrated and triangulated with quantitative data collected through household survey.

\section{Results and Discussion}

\subsection{Demographic Information of Sample Households (Respondents)}

Demographic information of respondents participated in this study is described in Table 2 . The study participants were predominantly male-headed households. About $93.5 \%$ and $6.5 \%$ were male-headed and female-headed households, respectively. Participation of few females in the study is due to cultural barriers that prohibited females. This could not limit participation of females in different livelihood activities in the study area. The mean age of the respondents is 41 . In this study, the age of respondents fall in 18-46 (74\%) and 
above $46(26 \%)$. This implies that most of the respondents were productive age groups. Of the respondents, about $66 \%$, $39 \%, 31 \%$ and $10 \%$ of respondents are illiterate, attained informal education, primary school and secondary school, respectively. This indicates that the majority of respondents were not attending formal education.

Table 2. Demographic characteristics of respondents.

\begin{tabular}{|c|c|c|c|c|c|c|c|}
\hline \multirow{2}{*}{ Characteristics } & \multicolumn{2}{|l|}{ Lowland } & \multicolumn{2}{|l|}{ Midland } & \multicolumn{2}{|l|}{ Highland } & \multirow{2}{*}{$\begin{array}{l}\text { Overall } \\
\text { Frequency }\end{array}$} \\
\hline & Frequency & $\%$ & Frequency & $\%$ & Frequency & $\%$ & \\
\hline \multicolumn{8}{|l|}{ Sex } \\
\hline Male & 146 & 93.0 & 68 & 95.8 & 145 & 92.9 & 359 \\
\hline Female & 11 & 7.0 & 3 & 4.2 & 11 & 7.1 & 25 \\
\hline Total & 157 & 100.0 & 71 & 100.0 & 156 & 100.0 & 384 \\
\hline \multicolumn{8}{|l|}{ Age } \\
\hline $18-30$ & 29 & 18.5 & 19 & 26.8 & 20 & 12.8 & 68 \\
\hline Above 46 & 39 & 24.8 & 16 & 22.5 & 45 & 28.8 & 100 \\
\hline Total & 157 & 40.9 & 71 & 18.5 & 156 & 40.6 & 384 \\
\hline Illiterate & 28 & 17.8 & 14 & 19.7 & 24 & 15.4 & 17.2 \\
\hline Informal education & 82 & 52.2 & 17 & 23.9 & 52 & 33.3 & 151 \\
\hline Primary school & 41 & 26.1 & 34 & 47.9 & 49 & 32.3 & 124 \\
\hline High school & 6 & 3.8 & 6 & 8.5 & 27 & 17.3 & 39 \\
\hline Diploma holder & 0 & 0.0 & 0 & 0.0 & 3 & 1.9 & 3 \\
\hline
\end{tabular}

\subsection{Constraints to Utilization of Land}

\subsubsection{Biophysical Constraints}

The majority of lowland agro ecology respondents (Table 3) mentioned that more constraint of the utilization of land were $(89.2 \%, 87.9 \%, 83.4 \%)$, of drought, crop damage/livestock loss, and poor soil fertility respectively. As well as, on the midland agro ecology more constraint observed on the utilization of land were $(89.2 \%, 81.1 \%, 78.8 \%)$, primitive agriculture, pest and diseases, and climate variability respectively. On the other hand on the highland agro ecology were $(98.6 \%, 80.6 \%, 81.2 \%)$, more constraint observed that shortage of gazing land, and crops /livestock damage by wildlife and limited land area respectively (Table 3). Widespread and high rates of soil erosion are cause serious problems of poor soil fertility. This finding is similar to [15] that stated, various factors such as livestock damage by wild animal, population growth, limited land area, expansion of agriculture and demands of wood are threatening the management of land and water resources in Ethiopia.

Table 3. Biophysical constraints of land resources utilization by agro-ecology.

\begin{tabular}{|c|c|c|c|c|c|c|}
\hline \multirow{3}{*}{ Biophysical factors } & \multicolumn{6}{|c|}{ Agro-ecology } \\
\hline & \multicolumn{2}{|l|}{ Lowland } & \multicolumn{2}{|c|}{ Midland } & \multicolumn{2}{|c|}{ Highland } \\
\hline & Yes $\%$ & No $\%$ & Yes $\%$ & No $\%$ & Yes\% & No $\%$ \\
\hline Low and erratic rainfall & 7.6 & 92.4 & 53.5 & 46.5 & 20.0 & 80.0 \\
\hline Poor soil fertility & 83.4 & 16.6 & 36.6 & 63.4 & 52.1 & 47.9 \\
\hline Limited land area & 15.3 & 84.7 & 33.8 & 62.2 & 81.2 & 19.8 \\
\hline Low land productivity & 76.4 & 23.6 & 36.6 & 66.4 & 35.0 & 65.0 \\
\hline Drought & 89.2 & 10.8 & 50.7 & 49.3 & 36.4 & 63.6 \\
\hline Shortage of gazing land & 28.7 & 71.3 & 64.8 & 35.2 & 98.6 & 1.4 \\
\hline Lack of water sources & 63.1 & 36.9 & 35.2 & 64.8 & 15.0 & 85.0 \\
\hline Topography & 35.0 & 65.0 & 38.8 & 66.2 & 32.9 & 67.1 \\
\hline Pest and diseases & 54.9 & 45.1 & 81.1 & 18.9 & 43.0 & 57.0 \\
\hline Primitive agriculture & 53.0 & 47.0 & 89.2 & 11.8 & 68.4 & 31.6 \\
\hline
\end{tabular}

Primitive agriculture is olden type of agriculture, less chemical fertilizers were used; instead, the green manures were used much. In the olden times, Agriculture hugely depended on human labor and lacked farming techniques and use bad quality seeds were used in farming in the olden days but now much better quality seeds are used for resistance to disease or high yield [16].

Land resources are limited and finite. The wise use of rural land resources with the best technologies, in the most rational and beneficial way possible, is crucial for the social and economic well-being of the country and its people Water depletion and land (natural resources) degradation, themselves the result of ever-increasing ecological imbalances, caused the recurrent drought and famine [17]. Similar findings have been made in other regions and sectors [18], stated that, the effects of climate variability and change are not experienced in isolation. For example, while a drought, population pressures, price fluctuations, market competition, technological innovation and other forces may cause severe challenges to agricultural production other natural and social systems may be subject to stresses such as economic decline, and cause degradation in air and water 
quality, urbanization, it results disease.

\subsubsection{Socio-economic Constraints}

Socio-economic constraints of land resources utilization in the three agro-ecology is given in Table 4 is that, on the lowland agro ecology, more constraint depend on socioeconomic factor were $98.7 \%, 80.9 \%, 80.0 \%$ was lack of scientific knowledge to use land, accessibility of market and Limited capital respectively (Table 4). As well as $(76.5 \%$, $67.6 \%$ ) of respondents on the midland agro ecology revealed, that more constraint depends on socio-economic factor was limited capital and Inaccessibility of market respectively. Even though $89.3 \%$ of respondents on the highland agro ecology revealed that more constraint depend on socio-economic factor was lack of infrastructures (Table 3). Similar study [19], stated that the major vegetable marketing constraints are related with non-availability of market/limited access to market, low price of product, lack of storage, and lack of transport, low quality product that cannot meet consumers demand and perish ability. Limitations in budget to expand SSI are also indicated as one of the main constraints.

Table 4. Socio-economic constraints of land resources utilization by agro-ecology.

\begin{tabular}{|c|c|c|c|c|c|c|}
\hline \multirow{3}{*}{ Socio-economic factor } & \multicolumn{6}{|c|}{ Agro-ecology } \\
\hline & \multicolumn{2}{|c|}{ Lowland } & \multicolumn{2}{|c|}{ Midland } & \multicolumn{2}{|c|}{ Highland } \\
\hline & Yes $\%$ & No $\%$ & Yes $\%$ & No $\%$ & Yes $\%$ & No $\%$ \\
\hline Lack ofinfrastructures & 87.9 & 12.1 & 49.3 & 50.7 & 89.3 & 10.7 \\
\hline Poor institutional structures & 87.9 & 12.1 & 43.7 & 56.3 & 60.7 & 39.3 \\
\hline Inaccessibility of market & 80.9 & 19.1 & 67.6 & 32.4 & 56.4 & 43.6 \\
\hline Limited capital & 80.0 & 20.0 & 76.5 & 23.5 & 65.6 & 34.4 \\
\hline Lack of science based knowledge and skil to use land & 98.7 & 1.3 & 56.3 & 43.7 & 72.9 & 21.1 \\
\hline
\end{tabular}

\subsubsection{Technological and Extension Services Constraints}

Agricultural machinery, lack of inputs, shortage of irrigation, lack of technological information and limited consultancy services are the major listed technological and extension service constraints of land resources utilization in the three agro-ecologies as described in Table 4. Similar findings have been made in other regions and sectors [20], stated that, loose of linkage between the research and extension, on the one hand, and lack of awareness by the extension services about the importance of these technologies were the gap and constraints of land resource utilization.

Table 5. Technological and extension services constraints of land resources utilization.

\begin{tabular}{|c|c|c|c|c|c|c|}
\hline \multirow{3}{*}{$\begin{array}{l}\text { Technological and Extension services } \\
\text { constraints }\end{array}$} & \multicolumn{6}{|c|}{ Agro-ecology } \\
\hline & \multicolumn{2}{|c|}{ Lowland } & \multicolumn{2}{|c|}{ Midland } & \multicolumn{2}{|c|}{ Highland } \\
\hline & Yes \% & No $\%$ & Yes \% & No $\%$ & Yes\% & No\% \\
\hline Agricultural machinery & 89.9 & 10.1 & 74.9 & 23.1 & 83.7 & 16.3 \\
\hline $\begin{array}{l}\text { Lack of inputs (Seed, } \\
\text { Fertilizer and pesticide) }\end{array}$ & 88.1 & 11.9 & 59.2 & 48.8 & 65.7 & 34.3 \\
\hline Shortage of irrigation & 91.4 & 8.6 & 83.6 & 16.4 & 90.7 & 9.3 \\
\hline Lack of technological information & 89.2 & 10.8 & 62.0 & 38.0 & 64.4 & 33.6 \\
\hline
\end{tabular}

\subsubsection{Policy and Law Enforcement Related Constraints}

Policy related constraints of land resources utilization in the three agro-ecology is given in Table 6. The major identified constraints were poor law enforcement, and natural resource use limiting laws and regulations in all agroecology. In the three agro-ecology, both problems are relatively similar. The majority (above $60 \%$ ) of respondents indicated policy related constraints of land resources utilization as explained in Table 6.

Weak governance and enforcement of national regulations on public land tenure at the local level have also promoted migration to the area, particularly as it pertains to the forested areas and forest glades just outside the BMNP boundary, which have seen a significant increase in agricultural encroachment over the past 20 years [10].

Table 6. Policy related constraints of land resources utilization by agro-ecology.

\begin{tabular}{llllll}
\hline & \multicolumn{2}{l}{ Agro-ecology } & & & \\
\cline { 2 - 6 } Policy related constraints & Lowland & & Midland & Highlad \\
\cline { 2 - 6 } & Yes \% & No \% & Yes \% & No \% & Yes \% \\
\hline Poor law enforcement & 77.1 & 22.9 & 62.0 & 38.0 & 62.1 \\
R use lim/iting laws regulation. & LR & 38.2 & 66.8 & 33.2 & 65.3 \\
\hline
\end{tabular}

\subsection{Level of Constraints in the Three Agro-ecologies}

Generally, as the study revealed that the following different constraints to show in the three-agro ecology were as follows:

On the midland agro ecology, about utilizing of land resource was Lack of infrastructures and other constraints was observed. In lowland agro ecology, about utilizing of 
land resource constraints was low and erratic rainfall, climate variability, lack of water sources, agricultural machinery, lack of knowledge and input was highly observed. At the highland agro- ecology, about utilizing of land resource was poor soil fertility, crops/livestock damage by wild animal and other constraints was observed. Common constraints in the three agro ecology of BER.

Generally, as the study revealed that the following similar constraints to show on the midland, lowland and highland agro ecology; about utilizing of land usage constraints was Lack of technologies, Governance and Institutional Constraints and land use limiting law and regulation implementations constraints was highly observed From FGD and in-depth interview, result revealed that on the lowland agro ecology; about utilizing of land resource constraints were Drought or degradation, lack of soil fertility and erosion. As well as on, the highland agro ecology was erosion and step mountain farming was the main constraints. Moreover, others are as follows:

\subsubsection{Lack of Science Based Knowledge and Skill}

Limited knowledge of marketing to produce high value crops production facilities, inadequate knowledge on utilization of land resource, inadequate knowledge base and low level of technical personnel on irrigation technologies (irrigation pumps, drip irrigation system, fertilizer, postharvest technologies, market opportunities and constraints, etc), inadequate baseline data and information on the development of water resources, lack of experience in design, construction and supervision of construction activities of constraints of natural resource.

\subsubsection{Governance and Institutional Constraints}

The gaps identified in this regard include lack of clarity in mandates, poor collaboration and networking and poor handing over of irrigation systems. At all levels, there exists low institutional capacity that is critical to enhance development of SSI with respect to development planning, design, implementation and operation and maintenance including irrigation advisory services.

\subsection{Trends of Land Status in BER of the Last 20 Years}

Table 7 show that trends of land holding probability in BER of the last 20 years were significantly associated with agro ecologies at $\mathrm{p}=(0.00)$ and trends of land productivity status in BER of the last 20 years were significantly associated with agro ecologies at $\mathrm{p}=(0.00)$. Land use and soil erosion changes are significant terrestrial processes altering biogeochemical processes, ecological dynamics, and the sustainability of agricultural systems [21]. Similar findings also [22] that stated, most land would have lower productivity, this would come from soil erosion and its conversion would involve significant negative climatic and biodiversity effects.

Table 7. Trends of land status response of respondent in BER over the last 20 years.

\begin{tabular}{|c|c|c|c|c|c|}
\hline \multirow{2}{*}{ Agro-ecology } & \multicolumn{5}{|c|}{ Land holding probability } \\
\hline & No change & Decreasing & Increasing & $\mathrm{X}^{2} / \mathrm{df}$ & P-value \\
\hline Midland & $5(7.0 \%)$ & $51(11.5 \%)$ & $15(21.1 \%)$ & & \\
\hline Lowland & $18(11.5 \%)$ & $139(88.5 \%)$ & $0(0.0 \%)$ & $36.52,4$ & .000 \\
\hline Highland & $11(7.9 \%)$ & $119(85.6 \%)$ & $9(6.5 \%)$ & & \\
\hline \multicolumn{6}{|c|}{ Crop land productivity } \\
\hline Midland & $2(8.7 \%)$ & $35(49.3 \%)$ & $34(47.9 \%)$ & & \\
\hline Lowland & $7(4.5 \%)$ & $138(87.9 \%)$ & $12(7.6 \%)$ & $63.46,4$ & .000 \\
\hline Highland & $14(10.1 \%)$ & $72(51.8 \%)$ & $53(38.1 \%)$ & & \\
\hline
\end{tabular}

Trends of Soil Status in BER over the Last 20 Years

The majority of respondents mentioned that more trends of soil status were $(78.9 \%, 91.7 \%, 97.8 \%)$ was decrease fertility in midland, lowland and highland, respectively. At $\mathrm{X}^{2}=25.10, \mathrm{df}=4, \mathrm{p}=.000$ there is significance difference in Soil fertility across the three agro ecologies while $(26.1 \%$, $66.9 \%, 68.3 \%$ ), were increase soil erosion in midland, lowland, highland, respectively at $\mathrm{X}^{2}=7.97, \mathrm{df}=4, \mathrm{p}=0.93$ there is no significance difference across soil erosion versus agro- ecologies.

In Ethiopia, land degradation in the form of soil erosion and declining fertility is serious challenges to agricultural productivity and economics growth [23]. Soil erosion by water is by far the greatest land degradation problem by selectivity removing organic matter and clay. Water erosion not only removes nutrients but also may reduce the soils chemicals capacity to retain added nutrients. Erosion reduces the thickness and the volume of soil available for water storage and root expansion for plants. Similar findings have been made in other regions and sectors [24] that stated, decline in soil fertility in tropical rain fed agriculture is becoming a serious problem for a growing number of people.

\section{Conclusion and Recommendations}

\subsection{Conclusion}

The findings showed that trends of land status in BER of the last 20 years are decreasing. Land holding, land productivity, soil fertility, crop species diversify and in highland habitat destruction are significantly associated agro ecology.

Low and erratic rainfall, climate variability, poor soil fertility, limited land area, lowland productivity, crop damage/livestock loss, drought, shortage of gazing land, lack of water sources, topography, pests, diseases, and primitive agriculture were biophysical constraints that 
influence agricultural land in BER.

In all agro-ecology, low and erratic rainfall, climate variability, drought, accessibility, lack of water sources, poor water quality was the common constraints of LR utilization. Lack of infrastructures, poor institutional structures, and inaccessibility of market, limited capital and lack of science based knowledge how to use land were Socio-economic constraints of land resources utilization in the three agroecology.

Lack of technology and lack of science based knowledge were among of the critical constraints that reported by majority of the respondents that limited them from utilizing of land. However, lowland productivity and primitive agricultural practice were among the least reported constraints that limited land utilization.

\subsection{Recommendations}

Based on the findings of the present study the following recommendations were suggested,

For Bale zone agricultural office and Bale Eco-Region Sustainable Management Program

a. Increasing the awareness of the local people about the overall risks of degradation of land and benefits of its land use

b. Increasing the awareness of the community about constraints of land utilization like to minimize fast rate of degradation..

c. Working jointly with local people to land use management and enhance the livelihood of local communities.

d. Supporting and giving direction of land use management experts have to give adequate attention to solve the problems of Low and erratic rainfall, Climate variability, Droughtin Bale Eco Region.

e. Prepare trainings for local people about the trends of land cover change and the effect of land degradation.

f. Follow up and law enforcing to avoid illegal agricultural expansion and giving much attention to improve land use management.

g. For FARM Africa and SOS Sahel Ethiopia and other development partners

h. Giving more attention on improving the science based knowledge and transferring technologies that are relevant for appropriate utilization of natural resources in BER to the concerned bodies.

i. Preparing community forums of discussion about the natural resources and rewarding those sacrifice more effort for conservation of NR

j. Supporting technically and financially further researches since the issue of natural resources is highly dynamic.

For Madda Walabu University

a. Supporting technically and financially further researches since the issue of natural resources is highly dynamic

b. Working closely with the local community about conservation of natural resources c. Promoting community ownership by transferring knowledge and technologies that are more relevant for improvement of responsible NR utilization

d. Working closely with zonal agricultural office and other stakeholders to reduce the effects of identified constraints from limiting utilization of LR in BER

\section{References}

[1] Auty, R. M. (1997). Natural Resources, the State and Development Strategy. Journal of International Development. (1997): 65163.

[2] Millennium Ecosystem Assessment, (2005). Ecosystems and Human Well-Being: Synthesis. Washington, DC: Island Press.

[3] Lee, D. R. (2009). Rural Poverty and Natural Resources: Improving Access and Sustainable Management.

[4] Colchester, M. (1994). Slave and enclave: the political ecology of equatorial Africa. World Rainforest Movement, Penang, Malaysia.

[5] Mohammad, A. and Adam, M. (2010). The impact of vegetative cover type on runoff and soil erosion under different land uses. 81: 97-103.

[6] Easter ling, W. E. (2003). Observed impact of climate change in agriculture and forestry. IPCC Workshop on the Detection and Attribution of the Effects of Climate Change, GISS, New York, 54.

[7] Codjoe, S. N. (2007). Integrating Remote Sensing, GIS, Census, and Socioeconomic Data in Studying the Population-Land Use/Cover Nexus in Ghana: A Literature Update Africa Development. 4 (2): 197-212.

[8] Gate, Z, Menale, K. and Mahmud, Y. (2006). Stakeholder analysis for sustainable land management (SLM) in Ethiopia: an assessment of opportunities, strategic constraints, information needs, and knowledge gaps.

[9] Eco-region news letter, (2016), no-1.

[10] Dereje, T. (2015). Frankfurt Zoological Society Conservation Development Centre Alec Crawford, International Institute for Sustainable Development.

[11] Freund and Williams, (1983). House hold Data Collection for the sample size is calculated using a standard formula.

[12] Garnevska, E. Guozhong, L. and Nicola, M. (2006). Factors for Successful Development of Farmer cooperatives in Northwest China. International Food and Agribusiness Management Review Volume 14 (4): 2011.

[13] Damianos, D. and Skuras, D. (1996). Farm business and the development of alternative farm enterprises: an empirical analysis in Greece. Journal of Rural Studies 12 (3), 273-283.

[14] Gary J. W. and Wilkinson R. L. (1997). Perceived profitability and farmers' conservation behaviour. Journal of agricultural economics, 48 (1), 13-21.

[15] Admasu, G. (2002). Proceedings of a MoWR/EARO/IWMI/ILRI international workshop held at ILRI, Ethiopian Rainwater. 
[16] Jishan, A. (2014). Farming-primitive and modern comparison.

[17] Belayhun, H. (2002). Present and future trends of natural resources (land and water) management in Ethiopian agriculture. Senior Land Evaluation Expert, Ministry of Agriculture, Addis Ababa, Ethiopia pp. 38.

[18] Cova, T. J. (2005). Public safety in the urban-wild land interface: Should fire-prone communities have a maximum occupancy? Natural Hazards Review 6: 99-108.

[19] Abraham, T. (2013). Value chain analysis of vegetables: the case of Habra and kombolcha woredas in oromia region, Ethiopia. Pp. 84.

[20] Paulos, D. (2002). Present and future trends in natural resources management in agriculture Research and development in land and water resources.
[21] Alkharabsheh, M. M. Alexandridis, T. K, Bilas, G. M (2013). Impact of land cover change on soil erosion hazard in Northern Jordan using remote sensing and GIS. Proscenia Environ Sci. 19: 912-921.

[22] Berkhout, F. (2012). Adaptation to climate change by organizations. Wiley Interdisciplinary reviews. 3 (1): 91-106.

[23] Mulugeta, L. (2004). Effects of Land use change on soil quality and Native Flora Degradation and Restoration in the Highlands of Ethiopia. Implication for sustainable Land Management Swedish university of Agricultural science Uppsala, Sweden.

[24] FAO, (2003). Soil Fertility Management in Support of Food Security in Sub-Saharan Africa. Rome: FAO pp. 12. 